\title{
Mineral and bone disease in renal transplantation
}

\author{
Ana Carina Ferreira1,2 iD, Aníbal Ferreira ${ }^{1,2}$ iD \\ ${ }^{1}$ Nephrology Department, Centro Hospitalar e Universitário de Lisboa Central, Hospital Curry Cabral, Lisbon, Portugal \\ ${ }^{2}$ Nova Medical School, Nova University, Lisbon, Portugal
}

\section{ABSTRACT}

Chronic kidney disease - mineral and bone disorders (CKD-MBD) tends to improve or to change phenotypically in the post-transplant period. Mineral and bone disorders post-transplantation (MBD-PT) seem to be associated with high fracture risk and cardiovascular morbidity, and so it is necessary to be aware of its presence to minimize the MBD-PT impact. In this article we summarize the features of MBD-PT.

Keywords: bone disease, fractures, mineral metabolism, renal transplantation

(C) 2021 Portuguese Journal of Nephrology \& Hypertension. Published by Publicações Ciência \& Vida This is an open access article under the CC BY-NC-ND license (http://creativecommons.org/licenses/by-nc-nd/4.0/).

\section{INTRODUCTION}

A successful kidney graft can fix various problems of chronic kidney disease (CKD). The chronic kidney disease mineral and bone disease (CKD-MBD) syndrome, composed of mineral abnormalities, renal osteodystrophy (ROD) and extra-osseous calcifications, tends to improve, to change, but not to wane.

Mineral and bone disorders post transplatation (MBD-PT) is dependent on CKD-MBD existing pre-transplant and on novel types of MBD-PT developed post-transplant, as a consequence of immunosuppression (mainly steroids and calcineurin inhibitors) or graft dysfunction ${ }^{1}$.

Furthermore, MBD-PT has implications for quality of life (bone pain) and mortality, similar to what happens in CKD-MBD in end-stage renal disease (ESRD) patients, as cardiovascular disease is a leading cause of death in ESRD and in renal transplanted patients ${ }^{2}$. Further, recent studies correlate CKD-MBD to post-transplant diabetes and graft dysfunction through nephrocalcinosis, and both are associated with loss of quality of live, mortality and healthcare costs 3,4 .

Knowing that MBD exists even in the transplant setting is a good start. We have to look at the problem and try to implement measures towards the improvement of morbid-mortality related to this disease in these patients.

\section{MINERAL ABNORMALITIES}

Mineral abnormalities in ESRD patients are very different from those after renal transplantation. In the first situation, hyperphosphatemia and hypocalcemia are frequent and related to phosphate excretion decline with consequent maladaptive hormonal responses. As phosphorus excretion is reduced, serum levels of the phosphaturic hormone fibroblast growth factor 23 (FGF23) increase. This will lead to a reduction in vitamin $\mathrm{D}$ activity and has a debatable action on parathyroid hormone $(\mathrm{PTH})^{5}$. PTH, in turn, will increase in an attempt to control calcium levels, triggering the efflux of calcium and phosphorus from the bone, increasing tubular reabsorption of calcium and tubular excretion of phosphorus and activating vitamin D. Nevertheless, non-functioning kidneys cannot reply properly to those actions, and in the end there will be a reduction of vitamin $D$, hyperphosphatemia and normo or hypocalcemia, along with hyperparathyroidism.

In the early post-transplant period, we will see what some authors call inappropriate hyperphosphatoninism ${ }^{6}$. Despite the reduction of FGF23 and PTH levels, the majority of renal transplanted patients will maintain higher levels than the normal population, and the maintenance of high PTH serum levels, although normal renal function, is observed in nearly $25 \%$ of patients ${ }^{7}$. Parathyroid cells have a long lifetime of nearly 20 years ${ }^{1}$, and monoclonal glandular hyperplasia happens ${ }^{8}$. In addition, renal denervation is associated with phosphaturia ${ }^{1,9}$ and renal grafts have tubular defects in calcium handling ${ }^{10}$. The resulting mineral abnormalities are hypophosphatemia and hypercalcemia $^{6,7}$. Hypophosphatemia affects nearly $90 \%$ of renal transplanted patients ${ }^{9,10}$. However, this event is self-limiting, and only $6-27 \%$ will maintain low serum levels of phosphorus ${ }^{11}$ in long-term follow-up. Relating to calcium, 5 to $55 \%$ of patients have a biphasic pattern, as hypocalcemia immediately post-transplantation is replaced by hypercalcemia in the $1^{\text {st }}$ week post-transplantation ${ }^{1,7}$. It worth saying that in a very recent study, hypercalcemia post-transplantation was associated with increased mortality risk ${ }^{12}$.

Treatment of mineral abnormalities in transplantation in not validated by randomized studies. Experts recommend vitamin D supplementation, according to calcium, phosphorus, PTH and 25-hydroxyvitamin D3 levels ${ }^{13}$. Hypophosphatemia can be corrected 
with calcitriol (in the absence of hypercalcemia) or with sodium or potassium monophosphate oral supplementation in severe cases. Hypercalcemia has limited treatment, and this is based on reducing PTH levels. Clinicians should avoid the use of hypercalcemic drugs.

\section{RENAL OSTEODYSTROPHY}

Renal osteodystrophy is classified according to turnover, mineralization and volume ${ }^{14}$, the TMV classification. All these three features (T-M-V) can be abnormal in ESRD patients, but the more common diseases in those patients are the ones related to high or low bone turnover and volume disturbances, with mineralization abnormalities being rarer than the previous ones ${ }^{15}$. Exceptionally, patients with CKD can be found to have only low bone volume, without abnormalities in mineralization and in turnover.

ROD before the transplant is an important factor for the existing ROD type in the post-transplant period. There is a scarcity of double bone biopsies studies (with bone biopsies performed immediately before and few months after renal transplant) for us to be sure about the evolution of ROD post-transplantation. The presumed loss of bone volume after transplant is one of the features we cannot assume without a double bone biopsy.

One of the first studies using a double bone biopsy was performed in $1991^{17}$. It encompassed 20 patients biopsied at baseline and 6 months after. Although the authors observed a reduction in the bone formation rate, bone volume was not different from the baseline. In recent years, 3 double bone biopsies studies were issued. In 2016, a Belgian study which included 36 renal transplanted patients was published ${ }^{18}$. The first bone biopsy was performed at baseline and the second after 12 months, with no differences in volume or mineralization. The study showed that the loss of trabecular bone was associated to corticoid therapy cumulative dosage. Three years later, a study from Brazil was published. It enrolled 31 patients submitted to double bone biopsies (at baseline and after 12 months). The study showed an improvement in cortical bone (regarding porosity and thickness), with no improvement in trabecular bone ${ }^{19}$. The third analysis, published also in 2019, from Finland, included 27 patients. In this study the first bone biopsy was performed while the patient was on dialysis, with a median of 15 months before the transplant, and a second bone biopsy was performed after 2 years of transplanta$\operatorname{tion}^{20}$. This study showed no changes in mineralization or volume, but a difference in turnover, evolved to a low turnover disease. Further, bone densitometry parameters and bone turnover markers did not relate with the histomorphometric findings. We also performed a recent double bone biopsy study and we found no differences in bone volume ${ }^{21}$, mineralization, with an increase in low bone turnover status.

From these recent works, we can assume that low-turnover bone disease increases and high-turnover bone disease declines after transplantation ${ }^{22}$. Osteomalacia appeared to be unusual ${ }^{22}$, and bone volume appeared to be similar to the pre-transplant value, possibly due to the current steroids-sparing immunosuppression protocols alongside supplementation of vitamin $D^{19}$.

Bone loss increases the risk of fractures ${ }^{23}$ and is a consequence of the inequality between bone resorption and bone formation.
Diagnosis of osteoporosis in the renal transplant patients is challenging, because in some, if not in the majority, bone loss is accompanied by other mineral bone disorders. Aside from bone loss, bone quality - in terms of mineralization, cortical porosity and trabecular bone architecture - influences the risk of fractures.

Since 2017, KDIGO guidelines have recommended evaluating bone volume in CKD patients through measurement of bone mineral density using dual-energy X-ray absorptiometry (DXA) ${ }^{24}$. Most studies assess bone volume after kidney transplantation with DXA. In a recent study, we found a good correlation between the bone volume measured by a bone biopsy and DXA findings, and found that DXA is an exam with a high specificity and negative predicted value, and therefor is a good exam to rule out the presence of osteopenia / osteoporosis ${ }^{21}$. Even so, DXA will not give any information about bone quality, which can be evaluated by high-resolution peripheral quantitative computed tomography (HR-pQCT) at the distal radius and tibia, reporting the volumetric density of cortical and trabecular regions ${ }^{25}$. However, this technique gives no information on mineralization, for which we need a bone biopsy ${ }^{26}$.

It is hypothesized that fracture risk is four-fold superior in transplanted patients than the general population ${ }^{1}, 34 \%$ higher than dialysis patients in the first 6 months post-transplantation, and slowly falls afterwards ${ }^{22}$. The percentage of patients submitted to renal transplantation that will suffer a fracture event is expected to be 10 to $25 \% 1,27$. Nonetheless, a recent meta-analysis did not reach the same conclusions, but the selected studies were dissimilar ${ }^{28}$. A study from Belgium into 502 patients transplanted between 2006 and 2013 presented a fracture incidence of 14.2 fractures per 1000 person-years, with a median period to initial fracture of 17 months ${ }^{29}$. Risk factors for fracture are various, with diabetes, pancreas-kidney transplantation, $\mathrm{BMI}<23$, white race, older age, female gender, immunosuppression, namely glucocorticoid dose and duration, abnormal PTH and, probably, hypophosphatemia ${ }^{8,22,23,30}$ the most relevant ones. Furthermore, it is important to stress that the importance of impaired bone quality in the fracture risk post-renal transplantation is not well defined ${ }^{31}$.

Since 2008, screenings for fracture risk have been possible using the Fracture Risk Assessment Tool (FRAX), developed by the World Health organization (WHO). Regrettably, this tool is not endorsed for kidney transplant recipients, or for persons younger than 40 years of age. Nevertheless, in 2014, Naylor and colleagues demonstrated that FRAX could predict fracture risk in renal transplant recipients ${ }^{32}$. As in CKD patients, this tool doesn't adjust the risk for the estimated glomerular filtration rate.

Recently two studies have been published, focusing on the use of bisphosphonates in post transplant to prevent bone loss. None proved to be effective ${ }^{19}$ and bisphosphonates should be reserved for the patients' with high risk of fracture. In the authors' opinion, patients should undergo a bone biopsy prior to treatment to show if we are in the presence of a reduced bone formation or a high bone resorption, situations with very different therapeutic implications ${ }^{26}$.

\section{VASCULAR CALCIFICATIONS}

Vascular calcifications are the third component of CKD-MBD, and are predictors of cardiovascular events and all-cause mortality over 
conventional risk factors in CKD patients ${ }^{2}$. We know that in ESRD patients, vascular calcifications progress faster than in the general population, increasing the risks of its consequences. The causes and progression of calcifications in uremic patients are attributed to hyperphosphatemia, changes in plasma PTH (low and high abnormal values), and to excessive bone resorption ${ }^{33}$. Potential new players are FGF23 $3^{34-37}$, klotho deficiency, which seems to stimulate osteoblastic transformation of vascular smooth muscular cells ${ }^{33}$, and sclerostin levels, a negative regulator of bone metabolism ${ }^{38}$, with some studies defending its protective role $\mathrm{e}^{39,40}$ through inhibition of vascular calcifications ${ }^{39,41}$ while other studies defend its association with mortality ${ }^{42}$ and degree of vascular calcification ${ }^{43}$.

In the transplant setting, in addition to traditional risks factors, secondary hyperparathyroidism and dialysis vintage seemed to be non-traditional risks factors for extra-osseous calcifications. Even so, renal transplant slows the progression of vascular calcification ${ }^{2}$ which is good.

\section{CONCLUSIONS}

Mineral abnormalities, bone-related disease and vascular calcification are frequent after renal transplantation, although different from those associated with non-functioning kidneys. The MBD-PT associated disorders tend to improve but, in some, patients, pharmacological and non-pharmacological interventions is still needed to reduce disability, cardiovascular disease and mortality.

Disclosure of potential conflicts of interest: none declared.

\section{References}

1. Evenepoel P. Recovery versus persistence of disordered mineral metabolism in kidney transplant recipients. Semin Nephrol 2013;33:191-203.

2. Cianciolo G, Capelli I, Angelini ML, et al. Importance of vascular calcification in kidney transplant recipients. Am J Nephrol 2014;39:418-26.

3. Wolf $\mathrm{M}, \mathrm{Molnar} \mathrm{MZ}$, Amaral AP, et al. Elevated fibroblast growth factor 23 is a risk factor for kidney transplant loss and mortality. J Am Soc Nephrol 2011;22:956-66.

4. Vervloet MG, Massy ZA, Brandenburg VM, et al. Bone: a new endocrine organ at the heart of chronic kidney disease and mineral and bone disorders. Lancet Diabetes Endocrinol 2014;2:427-36.

5. Liu S, Quarles LD. How fibroblast growth factor 23 works. J Am Soc Nephrol 2007;18:1637-47.

6. Evenepoel P, Meijers BK, de Jonge $H$, et al. Recovery of hyperphosphatoninism and renal phosphorus wasting one year after successful renal transplantation. Clin J Am Soc Nephrol 2008;3:1829-36.

7. Malluche $\mathrm{HH}$, Monier-Faugere MC, Herberth J. Bone disease after renal transplantation. Nat Rev Nephrol 2010;6:32-40.

8. Kalantar-Zadeh K, Molnar MZ, Kovesdy CP, Mucsi I, Bunnapradist S. Management of mineral and bone disorder after kidney transplantation. Curr Opin Nephrol Hypertens 2012;21:389-403.

9. Evenepoel P, Naesens M, Claes K, Kuypers D, Vanrenterghem Y. Tertiary 'hyperphosphatoninism' accentuates hypophosphatemia and suppresses calcitriol levels in renal transplant recipients. Am J Transplant 2007;7:1193-200.

10. Borchhardt K, Sulzbacher I, Benesch T, Fodinger M, Sunder-Plassmann G, Haas M. Low-turnover bone disease in hypercalcemic hyperparathyroidism after kidney transplantation. Am J Transplant 2007;7:2515-21.

11. Seeherunvong W, Wolf M. Tertiary excess of fibroblast growth factor 23 and hypophosphatemia following kidney transplantation. Pediatr Transplant 2011;15:37-46.

12. van der Plas WY, Gomes Neto AW, Berger SP, et al. Association of time-updated plasma calcium and phosphate with graft and patient outcomes after kidney transplantation. Am J Transplant 2020.

13. Kidney Disease: Improving Global Outcomes CKDMBDUWG. KDIGO 2017 Clinical Practice Guideline Update for the Diagnosis, Evaluation, Prevention, and Treatment of Chronic Kidney Disease-Mineral and Bone Disorder (CKD-MBD). Kidney Int Suppl (2011) 2017;7:1-59.

14. Moe S, Drueke T, Cunningham J, et al. Definition, evaluation, and classification of renal osteodystrophy: a position statement from Kidney Disease: Improving Global Outcomes (KDIGO). Kidney Int 2006;69:1945-53.

15. Malluche HH, Mawad HW, Monier-Faugere MC. Renal osteodystrophy in the first decade of the new millennium: analysis of 630 bone biopsies in black and white patients. J Bone Miner Res 2011;26:1368-76

16. Consensus development conference: diagnosis, prophylaxis, and treatment of osteoporosis. Am J Med 1993;94:646-50.
17. Julian BA, Laskow DA, Dubovsky J, Dubovsky EV, Curtis JJ, Quarles LD. Rapid loss of vertebral mineral density after renal transplantation. N Engl J Med 1991;325:544-50.

18. Evenepoel P, Behets GJ, Viaene L, D'Haese PC. Bone histomorphometry in de novo renal transplant recipients indicates a further decline in bone resorption 1 year posttransplantation. Kidney Int 2017;91:469-76.

19. Marques IDB, Araujo M, Graciolli FG, et al. A randomized trial of zoledronic acid to prevent bone loss in the first year after kidney transplantation. J Am Soc Nephrol 2019;30:355-65.

20. Keronen S, Martola L, Finne P, Burton IS, Kroger H, Honkanen E. Changes in bone histomorphometry after kidney transplantation. Clin J Am Soc Nephrol 2019;14:894-903.

21. Ferreira AC, Mendes M, Silva C, et al. Bone densitometry versus bone histomorphometry in renal transplanted patients: a cross-sectional study. Transpl Int 2021.

22. Alshayeb HM, Josephson MA, Sprague SM. CKD-mineral and bone disorder management in kidney transplant recipients. Am J Kidney Dis 2013;61:310-25.

23. Bellorin-Font E, Rojas E, Carlini RG, Suniaga $O$, Weisinger JR. Bone remodeling after renal transplantation. Kidney Int Suppl 2003:S125-8.

24. Ketteler M, Block GA, Evenepoel P, et al. Executive summary of the 2017 KDIGO Chronic Kidney Disease-Mineral and Bone Disorder (CKD-MBD) Guideline Update: what's changed and why it matters. Kidney Int 2017;92:26-36.

25. Bouquegneau A, Salam S, Delanaye P, Eastell R, Khwaja A. Bone disease after kidney transplantation. Clin J Am Soc Nephrol 2016;11:1282-96.

26. Ferreira AC, Cohen-Solal M, D'Haese PC, Ferreira A. The Role of Bone Biopsy in the Management of CKD-MBD. Calcif Tissue Int 2021;108:528-38.

27. Naylor KL, Li AH, Lam NN, Hodsman AB, Jamal SA, Garg AX. Fracture risk in kidney transplant recipients: a systematic review. Transplantation 2013;95:1461-70.

28. Sidibe A, Auguste D, Desbiens LC, et al. Fracture risk in dialysis and kidney transplanted patients: a systematic review. JBMR Plus 2019;3:45-55.

29. Evenepoel P, Claes K, Meijers B, et al. Bone mineral density, bone turnover markers, and incident fractures in de novo kidney transplant recipients. Kidney Int 2019;95:1461-70.

30. Buckley L, Humphrey MB. Glucocorticoid-induced osteoporosis. N Engl J Med 2018;379:2547-56.

31. Drueke TB, Evenepoel P. The bone after kidney transplantation. Clin J Am Soc Nephrol 2019;14: 795-7.

32. Naylor KL, Leslie WD, Hodsman AB, Rush DN, Garg AX. FRAX predicts fracture risk in kidney transplant recipients. Transplantation 2014;97:940-5.

33. Stompor T. Coronary artery calcification in chronic kidney disease: an update. World J Cardiol 2014;6:115-29.

34. Xiao Y, Peng C, Huang W, et al. Circulating fibroblast growth factor 23 is associated with angiographic severity and extent of coronary artery disease. PLoS One 2013;8:e72545.

35. Wolf M. Update on fibroblast growth factor 23 in chronic kidney disease. Kidney Int 2012;82: 737-47.

36. Udell JA, Morrow DA, Jarolim P, et al. Fibroblast growth factor-23, cardiovascular prognosis, and benefit of angiotensin-converting enzyme inhibition in stable ischemic heart disease. J Am Coll Cardiol 2014;63:2421-8.

37. Malluche HH, Blomquist G, Monier-Faugere MC, Cantor TL, Davenport DL. High parathyroid hormone level and osteoporosis predict progression of coronary artery calcification in patients on dialysis. J Am Soc Nephrol 2015;26:2534-44.

38. Moyses RM, Schiavi SC. Sclerostin, osteocytes, and chronic kidney disease - mineral bone disorder Semin Dial 2015;28:578-86.

39. Drechsler C, Evenepoel P, Vervloet MG, et al. High levels of circulating sclerostin are associated with better cardiovascular survival in incident dialysis patients: results from the NECOSAD study. Nephrol Dial Transplant 2015;30:288-93.

40. Viaene L, Behets GJ, Claes K, et al. Sclerostin: another bone-related protein related to all-cause mortality in haemodialysis? Nephrol Dial Transplant 2013;28:3024-30.

41. Claes KJ, Viaene L, Heye S, Meijers B, d'Haese P, Evenepoel P. Sclerostin: another vascular calcification inhibitor? J Clin Endocrinol Metab 2013;98:3221-8.

42. Goncalves FL, Elias RM, dos Reis LM, et al. Serum sclerostin is an independent predictor of mortality in hemodialysis patients. BMC Nephrol 2014;15:190

43. Qureshi AR, Olauson $\mathrm{H}$, Witasp A, et al. Increased circulating sclerostin levels in end-stage renal disease predict biopsy-verified vascular medial calcification and coronary artery calcification. Kidney Int 2015;88:1356-64

\section{ORCID}

Ana Carina Ferreira (iD) 0000-0002-1323-5293

Aníbal Ferreira (iD 0000-0002-3300-6033

\section{Correspondence to:}

Ana Carina Ferreira, MD

Nephrology Department, Centro Hospitalar e Universitário de Lisboa Central Hospital Curry Cabral, Lisbon, Portugal

Rua da Beneficência no 8; 1050-099 Lisbon, Portugal

E-mail: carina.ferreira@fcm.unl.pt 